\title{
El nuevo marco legal de la Investigación Biomédica en España (Ley 14/2007)
}

\author{
Salinas Sánchez AS. \\ Servicio de Urología del Complejo Hospitalario Universitario de Albacete. \\ Departamento de Ciencias Médicas de la Universidad de Castilla La Mancha.
}

Actas Urol Esp. 2008;32(3):273-275

La investigación en nuestro país ha experimentado un importante desarrollo en los últimos años. Según el mapa bibliométrico de España sobre Biomedicina y Ciencias de la Salud (http://www.isciii.es/mapabiomedico) en el período 1994-2002 y teniendo en cuenta todos los campos de la ciencia, España había incrementado su número de documentos y citas en un 8,8\% y 20,7\% respectivamente. En el ámbito de la Biomedicina, continúa situándose en segunda posición en cuanto al volumen de publicaciones (40,3\% del total de publicaciones en España), si bien se sitúa en primera posición en cuanto al volumen de citas (51,3\% del total).

Las diferentes normativas aprobadas en España a partir de 1970 han tenido, en cierto modo, que ver con este desarrollo. Sin embargo, la situación seguía siendo deficitaria en cuanto a legislación y recursos, fundamentalmente en función de la velocidad con la que actualmente avanza la tecnología en investigación biomédica. Estas circunstancias hicieron necesario que se plantease un marco legal, que diese cobertura a la nueva realidad científica facilitando su desarrollo y garantizando una investigación biomédica que respete los derechos de los ciudadanos.

Las directrices básicas sobre legislación y derechos en materia de investigación están ya recogidas en los clásicos Códigos Éticos (Código de Nüremberg de1947, Declaración de Helsinki de la Asociación Médica Mundial de 1964, el Informe Belmont de 1978 y el Convenio de Oviedo de 1997). También la Constitución Española de 1978 en el Artículo 20 reconoce y protege expresamente, entre otros, "el derecho a la producción científica y técnica y a la libertad de cátedra”, mientras que el artículo 44.2. establece que: "Los poderes públicos promoverán la ciencia y la investigación científica y técnica en beneficio del interés general”. Finalmente, los artículos
149.1.9 y 149.1.15 determinan que: "El Estado tiene competencia exclusiva sobre las siguientes materias: Legislación sobre propiedad intelectual e industrial y fomento y coordinación general de la investigación científica y técnica”.

Hasta la actual Ley 14/2007, diferentes normas y leyes han regulado la investigación biomédica en nuestro país de las que muchas de ellas siguen en vigor: Real Decreto (RD) 944/1978 y posterior $223 / 2004$ por el que se regulan los ensayos clínicos con productos farmacéuticos, Ley del Medicamento de 1990, Código de Ética y Deontología Médica de la Organización Médica Colegial 1999, la Ley de Garantías y Uso racional del Medicamento de 2006, la Ley 41/2002 de Autonomía del Paciente, las Leyes 35/1988 y 14/2006 sobre Técnicas de Reproducción Asistida, la Ley 42/1988 de Donación y Utilización de Embriones y Fetos Humanos o de sus Células, el RD 1301/2006 por el que se establecen las normas de calidad y seguridad para la donación, la obtención, la evaluación, el procesamiento, la preservación, el almacenamiento y la distribución de células y tejidos humanos, y las diversas Leyes sobre Donación, Extracción y Trasplantes de Órganos y Tejidos y Medicina Regenerativa (Ley 30/1979, RD 426/1980, RD 411/1996, RD 2070/1999, RD 174/2004).

La Ley 14/2007 de Investigación Biomédica aprobada por el Parlamento español el 3 de julio (B.O.E. 159 de 4 de julio de 2007), supone un gran avance al posibilitar el desarrollo de nuevos métodos de investigación. Además, permite aclarar y definir situaciones en el ámbito científico que, hasta el momento, estaban prohibidas o eran éticamente discutibles. Establece normas para el desarrollo de la investigación biomédica en nuestro país, dentro de un marco jurídico que garantice una investigación segura y respetuosa con los derechos de la población. El conjunto de materias regulado por la Ley se 
recogen en un preámbulo, ocho títulos, quince capítulos, noventa artículos, tres disposiciones adicionales, dos transitorias, una derogatoria y cinco finales.

En el preámbulo, se justifica la aprobación de la Ley sobre la base de los cambios metodológicos en investigación, la aparición de nuevas herramientas analíticas, la mayor necesidad de obtención, utilización, almacenaje y cesión de muestras biológicas, la mayor frecuencia de investigaciones con métodos invasivos en humanos, la mayor frecuencia de uso de gametos, embriones y células embrionarias y los avances en medicina regenerativa y terapia celular. Además, en este preámbulo se define la investigación biomédica como un instrumento clave para mejorar la calidad de vida, las expectativas de vida y el bienestar de los ciudadanos.

La Ley cuestiona la organización actual de la investigación biomédica, ahondando en la necesidad de un enfoque multidisciplinar y el desarrollo de la investigación traslacional, fomentando la participación tanto del Sistema Nacional de Salud, organismos autonómicos y sector privado, tratando de impulsar y fomentar la coordinación de todos estos estamentos con la finalidad de desarrollar políticas encaminadas a fomentar la investigación; fijando normas en ámbitos no regulados hasta la fecha como análisis genéticos, investigación con muestras biológicas humanas y biobancos.

Desde el punto de vista organizativo, se establece la creación de diversos órganos colegiados:

- Comités de Ética de Investigación, que deberán valorar la calidad de los proyectos presentados, la adecuación de los aspectos éticos y metodológicos del proyecto y la evaluación de riesgos y beneficios

- Comisiones de Garantía para la Donación y Utilización de Células y Tejidos Humanos. Dependiente del Instituto de Salud Carlos III, se crea como un órgano colegiado de carácter permanente y consultivo cuya misión será asesorar y orientar sobre la investigación y experimentación con muestras biológicas de naturaleza embrionaria humana, y contribuir a la actualización y difusión de los conocimientos científicos y técnicos en esta materia.

- Comité de Bioética de España. Dependiente del Ministerio de Sanidad y Consumo, su cometido principal será la implantación de códigos de buena práctica, la emisión de informes y opiniones acerca de aspectos conflictivos de la investigación biomédica, la realización de informes solicitados por el gobierno y otras entidades.
Alguno de los aspectos fundamentales que regula la Ley 14/2007 son:

- Los experimentos realizados en personas que se encuentran en situaciones "especiales" (embarazadas, mujeres lactantes, menores de edad, disminuidos psíquicos, etc...).

- Los procedimientos invasivos sobre seres humanos. Otorga las garantías necesarias para tomar muestras con seguridad y se prescribe el derecho que asiste al voluntario para recibir una compensación en caso de sufrir cualquier tipo de daño como consecuencia de los citados procedimientos.

- Los análisis genéticos para los cuales se debe recabar el consentimiento informado del voluntario y garantizar que sus resultados sean confidenciales y el derecho a no ser informado de dichos resultados.

- En relación a los biobancos, se regula su autorización, puesta en marcha y funcionamiento, estableciéndose los requisitos para la recogida y almacenaje de muestras y una serie de medidas para proteger a los donantes, como la necesidad de su consentimiento informado, gratuidad de la donación de tejidos y el derecho a retirar la muestra donada.

- La investigación con embriones humanos. Quizás sea este el aspecto más novedoso y controvertido de la nueva Ley que prohíbe explícitamente la constitución de preembriones y embriones humanos exclusivamente con fines de experimentación. Sin embargo, se permite la obtención de células troncales embrionarias humanas con fines terapéuticos o de investigación siempre que no comporte la creación de un preembrión. También, permite destinar a la experimentación los embriones sobrantes de técnicas de reproducción asistida, siempre que los progenitores consientan dicha utilización.

- La clonación humana. Es otra de las decisiones más controvertidas de esta Ley. La Ley prohíbe explícitamente la clonación humana pero permite la clonación terapéutica, decisión que ha desatado una importante polémica desde diversos sectores, ya que si la célula clonada se implantara con éxito podría llegar a desarrollarse, lo cual, según la opinión de muchos, convertiría a esta célula clonada en un verdadero embrión y, de esta manera, se incumpliría la prohibición de crear embriones para la investigación. La autorización y regulación, por primera vez en España, de la transferencia nuclear con 
fines terapéuticos iguala nuestra legislación a la de países como el Reino Unido, Bélgica, Suecia, Japón, Australia, Singapur, Israel y Corea.

Otro de los aspectos fundamentales de la Ley es que tiene como uno de sus ejes prioritarios el asegurar el respeto y la protección de los derechos fundamentales y libertades públicas del ser humano, en concreto, el respeto a los principios de integridad de las personas y la protección de la dignidad e identidad del ser humano, estableciendo que la libre autonomía de la persona es el fundamento del que se derivan los derechos específicos a obtener información y a otorgar consentimiento Además, la Ley establece el derecho a no ser discriminado, el deber de confidencialidad, el principio de gratuidad en las donaciones de material biológico y el deber de garantizar los estándares de calidad y seguridad en los experimentos realizados con seres humanos, tejidos y embriones. Se adoptan medidas tendentes a afrontar los riesgos y las consecuencias negativas que podrían acarrear cualquier investigación fundamentalmente en experimentos sobre genética y biología molecular.
La Ley garantiza también la libertad de investigación y de producción científica y el fomento, planificación, coordinación, producción y evaluación de la investigación biomédica a partir de los principios de eficacia e igualdad de oportunidades.

Finalmente, sienta las bases para el desarrollo de la carrera profesional investigadora en centros del Sistema Nacional de Salud, aspecto ampliamente demandado durante largo tiempo por los profesionales sanitarios. El nuevo marco legislativo fomenta la implantación de la investigación en los centros sanitarios como una práctica cotidiana.

En definitiva, se adecua la legislación española a los diversos convenios internacionales previamente suscritos por el Estado durante los últimos años y nos sitúa dentro del grupo de países con una legislación más "progresista" en materia de investigación biomédica.

Correspondencia autor: Dr. A.S. Salinas Sánchez Servicio de Urología. Complejo Hospitalario Universitario de Albacete Hermanos Falcó, 37 - 02006 Albacete Tel.: 967597235

E-mail autor: asalinas@pulso.com Información artículo: Editorial 